\title{
Humphry Davy and the Problem of Analogy
}

\section{Gregory Tate}

\section{University of St Andrews}

Analogy, the comparison of one set of relations to another, was essential to Humphry Davy's understanding of chemistry. Throughout his career, Davy used analogical reasoning to direct and to interpret his experimental analyses of the chemical reactions between substances. In his writing, he deployed analogies to organise and to explain his theories about the relations between physical processes and between the properties of different chemical elements and compounds. But Davy also regularly expressed two concerns about analogical comparison: first, that it was founded not on the rational interpretation of facts but on imaginative speculation; and second, that it was a kind of rhetoric, the persuasiveness of which depended not on material evidence but on misleading figures of speech. This article discusses the influences that informed Davy's ambivalent assessment of the value of analogy, and it examines the distinct yet overlapping ways in which this assessment was expressed in his notebooks, his lectures and treatises on chemistry, his philosophical writings, and his poetry.

Humphry Davy's views on analogy are summarised in a notebook that he used at the start of his career, in or before 1800. In some "Observations Relating to Existence," one of several fragmentary essays written in the notebook, Davy announces that:

All that we can hope for in physical \& metaphysical science ie the science of nature \& man is the discovery of new facts \& of new expressions of old facts.-By means of our immensely powerful instrument of language we are capable not only of reasoning upon known \& common things but likewise by making use of analogies \& the 
analytical method of reasoning upon unknown things the data being known things-it is from the extension of this reasoning to too great an extent that absurd \& ridiculous systems of all kinds have been formed. ${ }^{1}$

The conjunction of analytical reasoning and analogical thinking, Davy claims, is the basis not just of chemistry but of "science" in its broadest sense, the investigation of "nature \& man" which uses "known things" to theorise, discover, and verify "unknown things." But he also places limits on the legitimate scope of scientific knowledge, warning that, if pushed "to too great an extent," this mode of enquiry results not in "new facts" but in "absurd \& ridiculous systems," theories with no concrete foundation. He voices a similar reservation, about analogical thinking specifically, in his "Elucidations of Speculative Philosophy" in the same notebook: "The man of Genius must be acquainted with human nature \& his acquaintance must be founded not upon bare analogy; but upon an accurate observation of men."2

Analogies differ from other kinds of comparison because they identify correspondences not between things themselves but between their respective relations to their constituent parts, to their characteristics, or to other things. Analogy was a key part of the intellectual framework of Davy's chemistry, helping him to classify elements and compounds on the basis of similarities between their properties and between their interactions with other substances in chemical reactions. Sharon Ruston rightly points out that Davy considered analogy to be a "high-level thought process," and that it was vital to his understanding and presentation of himself as a "man of Genius" and philosopher:

Analogy was very much part of the perspective of his "true" philosopher: his world view was all-encompassing; analogy helped him to see the relations between the parts of the whole. It was very important to Davy that he not be thought of as narrow in his

\footnotetext{
${ }^{1}$ Humphry Davy, RI MS HD/22A, Royal Institution, 13.

2 Davy, RI MS HD/22A, 20.
} 
purview; he saw beyond the individual experiments in the laboratory to contemplate how they revealed the patterns in the whole world. ${ }^{3}$

Davy consistently used analogical thinking to identify and explain the dynamic yet uniform patterns and processes that determined the chemical transformations of matter and that, in his view, constituted the physical universe. But the aim of this article is to show that, while he relied on analogy, he was also troubled, throughout his career, by the doubts about its scientific validity which he expressed in his notebook. As well as signifying a correspondence between physical processes in the external world, the word "analogy" also denotes a comparative mode of reasoning and a figure of speech, and Davy was vexed by the uncertain relation between these different meanings. Analogies founded on facts were, for him, one of the bases of scientific knowledge, but the boundary between these legitimate analogies on the one hand, and analogies founded on nothing more than subjective speculation or linguistic metaphor on the other, was difficult to maintain.

Davy's problem of analogy was a particular example of the wider problem of induction that haunted eighteenth and nineteenth-century thinking about science. In his Treatise of Human Nature, David Hume put forward the sceptical argument that neither reason nor empirical evidence was a sufficient basis for inductive thought's progression from known particulars to unknown generalities:

Reason can never show us the connexion of one object with another, tho' aided by experience, and the observation of their constant conjunction in all past instances. When the mind, therefore, passes from the idea or impression of one object to the idea or belief of another, it is not determin'd by reason, but by certain principles, which associate together the ideas of these objects, and unite them in the imagination. ${ }^{4}$

\footnotetext{
${ }^{3}$ Sharon Ruston, "Humphry Davy and Priority."

${ }^{4}$ David Hume, A Treatise of Human Nature, eds. David Fate Norton and Mary J. Norton (Oxford: Oxford University Press, 2000), 64.
} 
The extent of Davy's direct knowledge of Hume is uncertain, although John Davy, in his Memoirs of the Life of Sir Humphry Davy, mentions his brother's youthful “acquaintance with the writings of all the more distinguished metaphysicians of modern times, as Locke, Hartley, Bishop Berkeley, Hume."5 And, in an 1801 letter to Davy, the poet Samuel Taylor Coleridge refers to Hume in an offhand way that suggests a shared familiarity with the philosopher's arguments. ${ }^{6}$ For Davy, the use of analogies to identify relations between objects was an exemplary instance of the inductive theorising on which chemistry depended, and his ambivalence towards analogy was rooted in the same unresolved questions that were raised by Hume's definition of induction. To what extent was inductive thinking an imaginative rather than a rational process? And could the exercise of the subjective imagination play any legitimate part in the experimental and theoretical methods of the sciences?

The urgency of these questions was sharpened, in Davy's case, by the difficulties involved in pursuing a career in chemistry at the start of the nineteenth century. In the view of Jan Golinski, Davy "was not a 'professional scientist." ${ }^{, 7}$ No such figure existed at the time; therefore, Golinski proposes, Davy had to construct his identity (or identities) for himself: he "was a self-made man-so much so that there was considerable puzzlement among his contemporaries as to what sort of person he actually was." His career can be understood as a series of intellectual and social performances through which he fashioned a variety of distinct yet overlapping personae. "He called himself a chemist, a philosopher, and a poet; but each of these terms had different connotations, and the combination of them in one individual was

\footnotetext{
${ }^{5}$ John Davy, Memoirs of the Life of Sir Humphry Davy, in The Collected Works of Sir Humphry Davy, ed. John Davy, 9 vols. (London: Smith, Elder, 1839-40), 1: 28.

${ }^{6}$ Samuel Taylor Coleridge to Davy, 3 February 1801, in Collected Letters of Samuel Taylor Coleridge, ed. Earl Leslie Griggs, 6 vols. (Oxford: Clarendon Press, 1966-71), 2: 672.

${ }^{7}$ Jan Golinski, The Experimental Self: Humphry Davy and the Making of a Man of Science (Chicago: University of Chicago Press, 2016), 3.
} 
unique." ${ }^{8}$ My argument in this article is that Davy's identities were informed by different styles of thought and expression, and that his views on analogy were shaped by a tension between those styles. On the one hand, his self-identification as a philosopher and a poet validated (to use the words of his early notebook) his interest in "metaphysical science" and his reliance on the "immensely powerful instrument of language." Imaginative analogies occupied an uncontentious place in philosophical and poetic thought. On the other hand, although Davy was not a professional scientist, he nonetheless subscribed to the methods of observational precision, objective description, and experimental verification which were emerging as the standardised conventions of scientific research in the early nineteenth century, and in which the status of analogical thinking was less secure.

However, it is important to emphasise that Davy's identities, and the modes of knowledge which they practised, were not rigidly segregated. He did not consider poetry and chemistry, for instance, to be straightforwardly opposed to each other. Dahlia Porter has argued that the young Davy, together with poets such as Coleridge and William Wordsworth, promoted a specifically Romantic definition of induction: they understood knowledge not as the classification of empirical data but as the work of "an active imagination," which linked facts together through analogy and which aspired to a "goal of synthetic unity." This "science of relations" promised to explain and demonstrate both the metaphysical unity championed in Romantic verse and the unity of nature as revealed by the physical sciences. ${ }^{10}$ In contrast to Porter, I think that Davy retained his interest in this synthetic understanding of analogy throughout his career; it was not confined to his early writings. But it was consistently checked by his suspicion that the speculative and rhetorical licence afforded by analogy might exceed the bounds of legitimate theorising. This ambivalent view of analogy is

\footnotetext{
${ }^{8}$ Golinski, The Experimental Self, 2.

${ }^{9}$ Dahlia Porter, Science, Form, and the Problem of Induction in British Romanticism (Cambridge: Cambridge University Press, 2018), 45.

${ }^{10}$ Porter, Science, Form, and the Problem of Induction in British Romanticism, 46.
} 
traceable throughout his diverse writings, from his lectures at the Royal Institution and his chemical treatises to his poems and philosophical dialogues.

The overlaps and tensions between Davy's different identities are concisely set out in a short essay on the "Parallels between Art and Science" which he published in 1807. The essay's argument hinges on an "analogy" between "the truths of the natural sciences" and "the productions of the refined arts." ${ }^{11}$ In both, Davy claims, "imagination, as well as reason, is necessary to perfection in the philosophical mind. A rapidity of combination, a power of perceiving analogies, and of comparing them by facts, is the creative source of discovery." The methods of art and science are comparable insofar as both rely on a negotiation between analogical thinking and factual evidence, and between imagination and reason. But Davy also distinguishes science from art, and specifically from poetry, asserting that "words are mutable and fleeting; and the genius of poetry is often dissipated in translation," and that, in contrast, "nature cannot decay: the language of her interpreters will be the same in all times. It will be an universal tongue, speaking to all countries, and all ages, the excellence of the work, and the wisdom of the Creator." 12 Although Davy wrote poems throughout his life, here he expresses a firm preference for the factual discoveries of the natural sciences, which offer a direct interpretation of the realities of the external world, ahead of the verbal and figurative productions of poetry. Insisting on a distinction as well as a parallel between poetry and science, this essay puts forward an opposition, between the permanent facts of nature and the unreliable significations of words, that recurs throughout Davy's writings on analogy.

\section{Analogy in Eighteenth and Nineteenth-Century Science}

\footnotetext{
${ }^{11}$ Davy, "Parallels between Art and Science," in The Collected Works of Sir Humphry Davy, 8: 307.

12 Davy, "Parallels between Art and Science," 308.
} 
Before discussing Davy's writings in detail, I will briefly consider the place of analogical thinking in British science more widely. Analogy has recently emerged as a prominent topic in scholarship on the history of science and on Romantic and Victorian literature, with researchers emphasising the way in which its epistemological ambiguity-its status as simultaneously factual, imaginative, and linguistic - acted as a bridge between different aspects of nineteenth-century British culture. In Darwin's Plots, her influential study of the narrative structures of Victorian evolutionary theory, Gillian Beer posits that analogy consists in "ranging two patterns of experience alongside each other, seeking their points of identity, and then using one pattern to extend the other." She comments that "there is always a sense of story - of sequence-in analogy, in a way that there need not be in other forms of metaphor," and that it is therefore particularly well-suited to articulating the historical narratives of variation and transformation on which Darwinian evolution depends. ${ }^{13}$ Devin Griffiths repeats this claim, arguing that, in nineteenth-century Britain, analogy was more important to the "descriptive' sciences" of geology and evolution, "which relied on description and imagination to elucidate natural pattern," than it was to experimental sciences such as chemistry. ${ }^{14}$ But the distinction between experiment and description was not as straightforward as this implies. Tim Fulford points out that, despite Davy's intermittent expressions of doubt about the reliability of words, his explanations of his experiments and theories are a form of narrative, which frequently rely on the rhetorical and figurative modes of language typically associated with literary writing. ${ }^{15}$

According to Kevin Lambert, the analogical identification of patterns and relations between natural phenomena was vital not just to evolutionary biology but also to the physical

\footnotetext{
${ }^{13}$ Gillian Beer, Darwin's Plots: Evolutionary Narrative in Darwin, George Eliot, and Nineteenth-Century Fiction, 3rd edn (Cambridge: Cambridge University Press, 2009), 74; Beer's italics.

${ }^{14}$ Devin Griffiths, The Age of Analogy: Science and Literature between the Darwins (Baltimore: Johns Hopkins University Press, 2016), 11.

15 Tim Fulford, "Science and Poetry in 1790s Somerset: The Self-Experiment Narrative, the Aeriform Effusion, and the Greater Romantic Lyric," ELH 85 (2018): 85-117.
} 
sciences in Victorian Britain. "In the second quarter of the nineteenth century," he writes, "analogies were used to bring order to the natural and social worlds by maintaining a coherent and collective experience across cultural oppositions such as the ideal and material, the sacred and profane, theory and fact."16 John Herschel's theorisation of physical science in his 1830 Preliminary Discourse on the Study of Natural Philosophy exemplifies this belief in analogical order and coherence. Herschel characterises the similarities between the phenomena of magnetism and those of electricity as instances of "those general analogies and parallels between great branches of science by which one strongly reminds us of another, though no direct connection appears;" such analogies are an "indication not to be neglected of a community of origin." ${ }^{17}$ Correspondence of pattern, for Herschel as for several other nineteenth-century science writers, indicates "community of origin," by which he means both a single physical process underpinning the phenomena and a shared origin in the providential wisdom of the Christian God. But this linking of the physical with the spiritual was not an innovation of the second quarter of the century; Davy often deployed analogy, in a similar way, to elucidate connections between natural processes and divine causes. In his "Parallels between Art and Science," for example, he sets out a natural theological analogy between "the excellence of the work, and the wisdom of the Creator."

Natural theology, and its endorsement of Christian faith, was an important aspect of the rhetoric of Davy's later writings. In the early stages of his career, however, his views on analogy were shaped by the more philosophically and politically radical thinking of Thomas Beddoes, the physician who, in 1798, employed the nineteen-year-old Davy at his Pneumatic Institution in Bristol to investigate the possible medical benefits of gases such as nitrous

\footnotetext{
${ }^{16}$ Kevin Lambert, “The Uses of Analogy: James Clerk Maxwell's 'On Faraday's Lines of Force' and Early Victorian Analogical Argument," British Journal for the History of Science 44 (2011): 61-2.

${ }^{17}$ John Herschel, A Preliminary Discourse on the Study of Natural Philosophy (London: Longman, Rees, Orme, Brown, and Green, 1830), 340.
} 
oxide. Beddoes was convinced of the importance of imagination in the development of new medical treatments:

The imagination, I presume, may very allowably range the unexplored recesses of Nature in quest of remedies for frequent and fatal disorders. If any thing that appears capable of supplying so great a desideratum should occur, you must of necessity, in applying it to use, be guided by views or expectations, previous to direct experience. To frame analogical hypotheses concerning the operation of untried agents (unless the hypotheses be absurd or contrary to well-established facts) can, therefore, bring no man's judgment into question. ${ }^{18}$

Echoing Hume, Beddoes argues that "direct experience" is an insufficient basis for the framing of inductive hypotheses. Instead, such hypotheses rely of necessity on the elaboration of analogies that are to some extent speculative. But Beddoes also acknowledges that these analogies must be verified by experience, and particularly by the controlled manipulation of experience that constitutes scientific experiment. Hypotheses cannot be "contrary to wellestablished facts," and "to adhere to speculation in opposition to the evidence of experiment is, I acknowledge, a degree of weakness, equal to the criminality of prevarication or direct falsehood." ${ }^{19}$ Mary Fairclough has suggested that "Beddoes roots his account" of the imagination, of which analogy was a key part, in a "materialist approach to enquiry" that was quickly repudiated by Davy, who in contrast defined the imagination as "transcendent," "unearthly," and "eternal." ${ }^{20}$ After his move in 1801 to the Royal Institution in London, where his work was guided by the conservative political attitudes of the aristocrats who managed and patronised the institution, Davy unequivocally distanced himself from Beddoes's radicalism and scientific materialism. However, there was nonetheless an

\footnotetext{
18 Thomas Beddoes and James Watt, Considerations on the Medicinal Use and on the Production of Factitious Airs, 2nd edn (London: J. Johnson, 1795), 8.

${ }^{19}$ Beddoes, Considerations on the Medicinal Use and on the Production of Factitious Airs, 9.

${ }^{20}$ Mary Fairclough, "Dr Thomas Beddoes and the Politics of the Imagination," Journal for Eighteenth-Century Studies 37 (2014): 83.
} 
important similarity between their understandings of the imagination. Both for Beddoes and for Davy, the imaginative construction of analogies was an essential step in the epistemological transition from particular experimental facts to comprehensive scientific theories.

Another, less direct, influence was the poet and natural philosopher Erasmus Darwin, whose writings Davy knew through Beddoes and through Coleridge. ${ }^{21}$ Darwin's integration of scientific argument with poetic expression became discredited in the years after his death in 1802 , as the trend towards intellectual and disciplinary specialisation in nineteenth-century Britain undermined the legitimacy of this sort of generic admixture. Davy's comments on him were often sceptical; as early as 1799 , he wrote that "Darwin's Theories seem to be daily loosing [sic] ground." ${ }^{22}$ But the two writers shared a concern with the relations between different kinds of analogy. In the Advertisement to his 1791 poem The Botanic Garden, Darwin announces that "the general design of the following sheets is to inlist Imagination under the banner of Science; and to lead her votaries from the looser analogies, which dress out the imagery of poetry, to the stricter ones, which form the ratiocination of philosophy." 23 Like Davy, Darwin distinguishes between the imprecise analogies of poetic imagery and the rigorous analogical reasoning of natural philosophy or physical science. But while Davy worries that the opposition between the two may be irreconcilable, Darwin confidently asserts that the figurative and imaginative analogies of poetry can operate as a form of science communication, helping to acquaint readers with the precise comparisons that underpin the theories of science, specifically, in the case of this poem, the Linnaean system of botanical taxonomy.

\footnotetext{
${ }^{21}$ See Martin Priestman, The Poetry of Erasmus Darwin: Enlightened Spaces, Romantic Times (Farnham: Ashgate, 2013), 15.

22 Davy to Henry Penneck, 26 January 1799, http://www.davy-letters.org.uk (accessed 16 November 2018). This website will be superseded by The Collected Letters of Sir Humphry Davy, eds. Tim Fulford and Sharon Ruston, 4 vols. (Oxford: Oxford University Press, forthcoming).

${ }^{23}$ Erasmus Darwin, The Botanic Garden (London: J. Johnson, 1791), v.
} 
"In the last year of his life," according to his brother, Davy characterised Darwin and Beddoes as essentially literary thinkers: Beddoes had a "wild and active imagination, which was as poetical as Darwin's." ${ }^{24}$ This implies a distinction between the speculative imagination and the (presumably more measured) kind of inductive reasoning that informed Davy's investigations of chemistry. But Beddoes and Darwin identified analogy as both an imaginative process and an instrument of science, a view that was influenced by their knowledge of the associationist philosophy of the Scottish Enlightenment, to which they were introduced while studying medicine at the University of Edinburgh in the second half of the eighteenth century. ${ }^{25}$ In its scepticism towards a priori ideas and its definition of knowledge as the product of experience, associationism was an important intellectual support for the inductive and experimental protocols of science as they were codified over the course of the eighteenth and nineteenth centuries. For the associationists, analogy was one of the key methods through which the mind progressed from the observation of particular facts to the formation of general propositions, and the emphasis on analogy's importance to scientific theorising in the work of Darwin, Beddoes, Davy, and numerous Victorian scientists is founded in part on the prominence of analogical thinking in associationist philosophy of mind.

Hume, for instance, despite his denial of the rationality of induction, insists in his Enquiry Concerning Human Understanding that the development of analogies based on experience is the root of knowledge of the external world: "All our reasonings concerning matter of fact are founded on a species of ANALOGY, which leads us to expect from any cause the same events, which we have observed to result from similar causes." ${ }^{26}$ Hume emphasises the point, which is of crucial significance to scientific analogy and especially to the analogies

\footnotetext{
${ }^{24}$ Quoted in John Davy, Memoirs of the Life of Sir Humphry Davy, 49.

${ }^{25}$ See Fairclough, "Dr Thomas Beddoes and the Politics of the Imagination," 81; and Priestman, The Poetry of Erasmus Darwin, 13.

${ }^{26}$ Hume, An Enquiry Concerning Human Understanding, ed. Peter Millican (Oxford: Oxford University Press, 2007), 76 .
} 
of Davy's chemistry, that this kind of inductive thinking depends on the observation of a range of similar objects, events, and patterns of cause and effect:

It is only when two species of objects are found to be constantly conjoined, that we can infer the one from the other; and were an effect presented, which was entirely singular, and could not be comprehended under any known species, I do not see, that we could form any conjecture or inference at all concerning its cause. If experience and observation and analogy be, indeed, the only guides which we can reasonably follow in inferences of this nature; both the effect and the cause must bear a similarity and resemblance to other effects and causes, which we know, and which we have found, in many instances, to be conjoined with each other. ${ }^{27}$

The mental principle of association groups the findings of "experience and observation" into "species of objects" by identifying them as effects of particular causes. Analogy, Hume suggests, constitutes a higher-level elaboration of this process: it links together species of objects, and their causal relations, on the basis of their similarity, and therefore enables the mind to identify patterns in the external world. This account was influential in nineteenthcentury definitions of science as the study of the dynamic processes of nature, and it also legitimised the extension of analogies beyond the apparent limits of the natural sciences, as writers traced correspondences between scientific theories and metaphysical, sociopolitical, or aesthetic beliefs. To the extent that Davy's writings promote a view of analogy as an agent of epistemological synthesis and an expression of ontological unity, they build not just on Romantic theories of the imagination, but also on the associationist model of induction that informed his understanding of the scientific method.

\section{Analogy in Davy's Chemistry}

\footnotetext{
${ }^{27}$ Hume, An Enquiry Concerning Human Understanding, 107-8; Hume's italics.
} 
Davy frequently reinvented himself over the course of his career: his philosophical and religious beliefs, his political opinions, and his self-definition altered as he aged and as he moved between different institutional and intellectual contexts. But his conviction of the importance of analogy to chemistry was strikingly consistent. Throughout his science writings, it is one of the most prominent means through he organises and explains his experimental findings and his theoretical arguments. The adjective "analogous" is a keyword in his 1800 Researches, Chemical and Philosophical, Chiefly Concerning Nitrous Oxide; in his 1802 Syllabus of a Course of Lectures on Chemistry, Delivered at the Royal Institution of Great Britain; and in his 1812 Elements of Chemical Philosophy. He employs the word to identify correspondences between a diverse range of data: chemical reactions; the sensations prompted by nitrous oxide and other intoxicants; ${ }^{28}$ the "physical properties" of groups of elements and compounds; ${ }^{29}$ the general "laws" of chemistry and physics; and the phenomena of physical processes such as electricity and magnetism. ${ }^{30}$ In each case, Davy's use of the word indicates that the most accurate way to describe and classify a set of processes, substances, or laws is to identify them as analogous to known equivalents.

However, Davy's ambivalence towards analogy was equally consistent. On the first page of the Syllabus of his 1802 course of lectures at the Royal Institution, he asserts that "the sciences are classes of different facts associated together by analogy," and that "the theories which represent them are connected propositions, in which, by means of that faculty of the mind named abstraction, one term is made to represent a number of other terms, which themselves stand for ideas." ${ }^{31}$ He identifies scientific theorising as an inductive process that

\footnotetext{
${ }^{28}$ Davy, Researches, Chemical and Philosophical, Chiefly Concerning Nitrous Oxide, in The Collected Works of Sir Humphry Davy, 3: 96 and 271.

${ }^{29}$ Davy, A Syllabus of a Course of Lectures on Chemistry, Delivered at the Royal Institution of Great Britain, in The Collected Works of Sir Humphry Davy, 2: 354.

${ }^{30}$ Davy, Elements of Chemical Philosophy, in The Collected Works of Sir Humphry Davy, 4: 37 and 124.

${ }^{31}$ Davy, A Syllabus of a Course of Lectures on Chemistry, 329.
} 
operates on empirical facts which are "associated together by analogy;" the resulting ideas are then arranged, represented, and communicated through linguistic terms and propositions. Analogical comparison is essential to the sciences' elaboration of theories from facts. Yet in the Advertisement which is prefixed to the Syllabus, Davy places fact and analogy in opposition to each other, commenting that "the classification of substances adopted" in his lectures "is founded rather upon facts than analogies; and in consequence, certain bodies have been placed amongst the simple principles, which, from their resemblance to other bodies of known composition, have been generally arranged in the class of compounds." 32 Davy here imposes a limit on the scientific value of analogy. The resemblance between the bodies in question and other known compounds is not a sufficient basis for their classification; instead, their place in his system is determined by the fact that they have not yet been experimentally decompounded, and therefore appear to be elements or "simple principles."

The first of Davy's 1802 lectures, “A Discourse Introductory to a Course of Lectures on Chemistry," puts forward a sweeping narrative of intellectual progress, celebrating not just chemistry but natural science in general as a form of knowledge that is at the same time epistemologically precise, aesthetically pleasing, practically useful, and socially respectable. Davy's considerations of the different branches of science in this discourse, and of their respective degrees of rigour and utility, frequently depend on assessments of the kinds of analogy employed by them. He claims, for example, that, without the aid of chemical analysis, "the mind of the mineralogist" is baffled and "perplexed by endeavours to discover the loose and varying analogies between the colours, the shapes, and the weights of different substances." Davy judges analogies by their results: the mineralogist's analogical comparisons of colours, shapes, and weights are "loose" because they fail to reveal the sort of consistent or coherent patterns that might inform the classification of minerals or the

\footnotetext{
32 Davy, A Syllabus of a Course of Lectures on Chemistry, 328.
} 
explanation of their composition and origin. In contrast, he tells his audience, "medicine and physiology" have "derived from chemistry most of their practical applications, and many of the analogies which have contributed to give to their scattered facts order and systematic arrangement." ${ }^{\prime 33}$ But he also cautions that some physiological researchers have been carried away by the ambition of their theoretical systems:

Speculative philosophers have been guided rather by the analogies of words than of facts. Instead of slowly endeavouring to lift up the veil concealing the wonderful phænomena of living nature; full of ardent imaginations, they have vainly and presumptuously attempted to tear it asunder. ${ }^{34}$

As Kurtis Hessel points out, "because they sought to transmit unfamiliar ideas via familiar analogues, Davy's lectures embraced figural language" such as the conventional (and arguably clichéd) metaphor of the veil hiding the face of nature. ${ }^{35}$ Davy reworks this metaphor as an analogy: precise and rigorous investigation effects the slow lifting up of this veil, while speculative theorising tries in vain to "tear it asunder." The gendered dynamic of the veil metaphor, in which the man of science reveals the secrets of a feminised nature, means that the analogy carries with it connotations of sexual violence; it supports Davy's broader argument for the social respectability of natural science by suggesting that speculative philosophy, in contrast, is morally as well as intellectually dangerous. ${ }^{36}$ Davy's rhetorical device encapsulates some of the ambiguities in his understanding of analogy, as he uses an analogical figure of speech to criticise linguistic analogies, and to insist that

\footnotetext{
${ }^{33}$ Davy, "A Discourse Introductory to a Course of Lectures on Chemistry," in The Collected Works of Sir Humphry Davy, 2: 313

${ }^{34}$ Davy, "A Discourse Introductory to a Course of Lectures on Chemistry," 314.

${ }^{35}$ Kurtis Hessel, "The Romantic-Era Lecture: Dividing and Reuniting the Arts and Sciences," Configurations 24 (2016): 515.

${ }^{36}$ For a discussion of the sexual politics of the veil metaphor, see Ludmilla Jordanova, Sexual Visions: Images of Gender in Science and Medicine between the Eighteenth and Twentieth Centuries (Madison: University of Wisconsin Press, 1989), 87-110.
} 
legitimate scientific knowledge must be founded not on words but on the analogical connection of empirical facts.

Davy reiterates his opposition between linguistic imagination and scientific rigour in the peroration to his discourse, but again there are tensions within the language that he uses to articulate this opposition. He extols science's preference for "things" ahead of "words," but he also uses that preference to support his claim that scientific study can lead to knowledge of questions with no direct link to the material things and physical processes of nature:

The man who has been accustomed to study natural objects philosophically, to be perpetually guarding against the delusions of the fancy, will not readily be induced to multiply words so as to forget things. From observing in the relations of inanimate things fitness and utility, he will reason with deeper reverence concerning beings possessing life; and perceiving in all the phenomena of the universe the designs of a perfect intelligence, he will be averse to the turbulence and passion of hasty innovations, and will uniformly appear as the friend of tranquillity and order. ${ }^{37}$

These sentences set out a defence of natural theology and political conservatism which hinges on a series of associations so loose that they arguably do not qualify as analogies. The first is between "inanimate things" and "beings possessing life." Davy does not elaborate on the details of the correspondence between these two groups, but his argument is evidently that the "fitness and utility" of both embody "the designs of a perfect intelligence" and demonstrate the providential order of the physical universe. He then, in a second submerged analogy, implies an equivalence between this order and the "tranquillity and order" that characterise the proper conduct of political and social life. Andrea Henderson has argued that, in the work of Victorian physicists, analogy is presented as an "equalizing" mode of thought, which defines physical phenomena such as electricity and magnetism "in terms of reciprocal

\footnotetext{
${ }^{37}$ Davy, “A Discourse Introductory to a Course of Lectures on Chemistry,” 326.
} 
tensions and mutually sustained energies rather than the dominating power of discrete agents," and which is therefore "in striking conformity" with the "reformist political ideology" that was widely influential in Victorian Britain. ${ }^{38}$ Davy here illustrates Henderson's general argument that scientific analogy is often also political. However, he uses the analogy between political relations and the "relations of inanimate things" to promote a hierarchical (rather than equalising) model of nature and society, endorsing the reactionary conservatism, and suspicion of "hasty innovations," that shaped the politics of the British establishment in the decades after the French Revolution.

The 1802 discourse sets a pattern for Davy's handling of analogy that recurs throughout his writings. It claims that only analogies based on empirical facts are permissible in scientific theorising; it criticises analogies based on words rather than on facts; but it also uses both kinds of analogy, factual and figurative, to expand the remit of physical science beyond the empirical and to argue for correspondences between scientific knowledge and political and metaphysical beliefs. In the Elements of Chemical Philosophy, a text which aims to summarise the findings of his experiments and to set out a systematic classification of material substances based on those findings, Davy writes that:

The foundations of chemical philosophy are, observation, experiment, and analogy. By observation, facts are distinctly and minutely impressed on the mind. By analogy, similar facts are connected. By experiment, new facts are discovered; and, in the progression of knowledge, observation, guided by analogy, leads to experiment, and analogy confirmed by experiment, becomes scientific truth. ${ }^{39}$

Scientific method, in this formulation, commences with the observation of facts before proceeding to a sustained negotiation between analogy and experiment. Davy allows that speculative analogies play a part in this method. But the key distinction between "chemical

\footnotetext{
${ }^{38}$ Andrea K. Henderson, Algebraic Art: Mathematical Formalism and Victorian Culture (Oxford: Oxford University Press, 2018), 130-31.

${ }^{39}$ Davy, Elements of Chemical Philosophy, 2.
} 
philosophy" and the sort of imaginative induction that, according to Hume, constitutes general knowledge is that the chemist's hypothetical connections of facts are confirmed (or not) by the discovery of new and corroborative facts through the processes of experiment. In the historical survey of chemical knowledge that opens Elements of Chemical Philosophy, Davy utilises this model of scientific analogy to distinguish modern chemistry from preRenaissance alchemy. The "vain imagination," "wanderings of genius," and abstruse "systems of logic" that shaped the theories of the alchemists, he asserts, "were founded rather upon the analogies of words than upon the relations of things; and they were more calculated to conceal error, than to discover truth." 40

The bulk of Elements of Chemical Philosophy consists of accounts of Davy's experiments and explanations of his taxonomy of the different forms of matter. Most of the analogies put forward in the text are strictly chemical and material in scope; perhaps the most important is the claim that "as far as our knowledge of the nature of compound bodies has extended, analogy of properties is connected with analogy of composition," which is arguably the foundational principle informing Davy's research on the properties of and interactions between chemical substances. ${ }^{41}$ In keeping with his definition of chemistry as a mutually correcting exchange between analogical hypotheses and experimental tests, he acknowledges that his classification of substances is provisional, and he looks forward to a future in which chemical theories are more precise:

It is contrary to the usual order of things, that events so harmonious as those of the system of the earth, should depend on such diversified agents, as are supposed to exist in our artificial arrangements; and there is reason to anticipate a great reduction in the number of the undecompounded bodies, and to expect that the analogies of nature will be found conformable to the refined operations of art. The more the phenomena of the

\footnotetext{
${ }^{40}$ Davy, Elements of Chemical Philosophy, 14.

${ }^{41}$ Davy, Elements of Chemical Philosophy, 358.
} 
universe are studied, the more distinct their connection appears, the more simple their causes, the more magnificent their design, and the more wonderful the wisdom and power of their Author. ${ }^{42}$

Here, again, Davy's reasoning relies on a number of implicit and loose analogies. He posits a correspondence between "the usual order of things" (by which he means, apparently, the physical and metaphysical constitution of the universe as a whole) and the events of "the system of the earth," the terrestrial processes studied in experimental chemistry. But there is a disanalogy between these harmonious processes and "our artificial arrangements." In the future, he hopes, chemistry will be simplified through "a great reduction in the number of the undecompounded bodies," substances whose chemical structures remain at present unresolved. This goal is to be attained, presumably, by the further framing and experimental testing of analogical hypotheses, and, when it is realised, "the analogies of nature will be found conformable" to the artificial analogies constructed through experiment. This conformity between science and nature is possible, Davy suggests in the final sentence, because the "phenomena of the universe"-both the physical phenomena of the external world and the mental phenomena of scientific theorising-are connected analogically through their shared causes, which can ultimately be reduced to a singular cause: "the wisdom and power of their Author."

\section{Analogy in Davy's Poetry and Speculative Philosophy}

Despite its technical focus, Elements of Chemical Philosophy finds room for analogical arguments about the metaphysical origins of chemical processes. This kind of analogy was a conventional feature of natural theology, but in some of his other writings Davy gives free

\footnotetext{
${ }^{42}$ Davy, Elements of Chemical Philosophy, 42.
} 
rein to more idiosyncratic speculations. Jan Golinski argues that there is "only a superficial kind of unity among Davy's varied publications," and that he utilises "the different textual genres" of his work to a develop a broad range of "authorial personae."43 Consolations in Travel, written as Davy travelled through Europe in the late 1820s and published posthumously in 1830 , supports this observation to an extent. The authorial persona presented in this series of philosophical dialogues is arguably that of a speculative philosopher rather than a specialist chemist; Davy's aim is to integrate the most recent theories of the physical sciences with bold metaphysical conjectures. In the first dialogue his narrator meets with a supernatural entity, "the Genius," who transports him to Saturn. His guide expresses sympathy with the narrator's understandable bafflement at this turn of events, and at the alien landscapes and extraterrestrial beings to which he is introduced: "I know what your feelings are,' said the Genius: 'you want analogies and all the elements of knowledge to comprehend the scene before you." 44 The inhabitants of Saturn are identified as more advanced than humanity, and the genius spends much of this dialogue trying to supply the narrator with analogies capable of illustrating their superiority:

"As I cannot describe to you the organs of these wonderful beings, so neither can I show to you their modes of life; but as their highest pleasures depend upon intellectual pursuits, so you may conclude that those modes of life bear the strictest analogy to that which on the earth you would call exalted virtue."45

The Genius "cannot describe" the physical constitution of the beings because their organs comprise a form of matter which is unknowable through the human senses: "with higher natures, finer and more etherial kinds of matter are employed in organization, substances that bear the same analogy to common matter that the refined or most subtle gases do to common

\footnotetext{
${ }^{43}$ Golinski, The Experimental Self, 181.

${ }^{44}$ Davy, Consolations in Travel; or, the Last Days of a Philosopher, in The Collected Works of Sir Humphry Davy, 9: 242.

${ }^{45}$ Davy, Consolations in Travel, 243-4.
} 
solids and fluids." "46 The Genius's analogies convey both a moral comparison, between the beings" habitual "mode of life" and the virtue rarely attained by humanity, and a material correspondence between the properties of the different forms of "common matter" and those of the ether, the hypothetical substance that, in the opinion of most nineteenth-century scientists, pervaded space and acted as the medium of the transmission of light and radiant heat. This ether, according to the Genius, might also provide a material form to "higher natures." Scientific theory is enlisted here in the service of speculative fiction, via an analogy which has been severed from any foundation in observed fact.

This degree of imaginative freedom is not, however, maintained throughout Consolations in Travel as a whole. The Genius disappears after the first dialogue, and the second half of the text is dominated by the figure of the Unknown, a preternaturally wise chemist whom the narrator and his companions meet during their travels around Europe. The Unknown is sternly critical of overambitious analogies. Discussing the "new and extraordinary views in electricity" which have been recently revealed by "the progress of science" and "applied by speculative reasoners to solve some of the mysterious and recondite phenomena of organized being," he cautions that "the analogy is too remote and incorrect; the sources of life cannot be grasped by such machinery; to look for them in the powers of electro-chemistry is seeking the living among the dead." ${ }^{47}$ Davy himself was the most influential proponent of what the Unknown terms "electro-chemistry;" his experimental isolation of chemical elements frequently depended on the decomposition of compound substances by the electrical current of a voltaic battery. But, through the voice of the Unknown, Davy insists that there is no legitimate analogy between this process and the physiological processes that characterise “organized being." He espouses a dualist separation of the properties of living things from those of "dead" matter, a distinction which rejects the

\footnotetext{
46 Davy, Consolations in Travel, 245.

${ }^{47}$ Davy, Consolations in Travel, 335.
} 
kind of analogy between material and vital phenomena put forward with such abandon in the first dialogue (and propounded, as well, in the peroration to his 1802 discourse).

Yet although the Unknown censures this "remote and incorrect" comparison, he is not hostile to scientific analogy in general. In the fifth dialogue he enumerates "the intellectual qualities necessary for discovery, or for the advancement of the science" of chemistry, advising, among other things, that "the imagination must be active and brilliant in seeking analogies; yet entirely under the influence of the judgment in applying them," and that, "in detailing the results of experiments, and in giving them to the world, the chemical philosopher should adopt the simplest style and manner; he will avoid all ornaments, as something injurious to his subject." ${ }^{48}$ The presence of such sentiments in a text written in the final year of Davy's life demonstrates the consistency of his views on analogy. As in his 1802 lectures and in the 1812 Elements of Chemical Philosophy, he assigns the analogical imagination a valid role in the methods of chemistry, while also insisting that hypothetical analogies must be carefully interrogated and that figures of speech such as rhetorical analogies are best avoided altogether. And his identification of scientific theorising as a collaboration between two mental faculties, a speculative imagination and a critical and rational judgment, recalls the comment, written in his notebook thirty years before, that science relies both on analogical thinking and on "the analytical method of reasoning."

This balanced assessment of analogy, poised between appreciation of its explanatory power and concern about its imaginative and rhetorical excesses, is characteristic of most of Davy's writings. But there are also examples in his work of an alternative, unequivocally critical, view. In another notebook which he used around 1800, Davy wrote:

That Man must indeed be badly organized whom Nature is incapable of instructing. The Theorising habit in a sound mind can counteract for a short time only the love of

\footnotetext{
${ }^{48}$ Davy, Consolations in Travel, 365-6.
} 
seeing things in their real light \& the illusions of the imagination in proportion as they often occur \& are destroyed by facts will become less vivid \& less capable of permanently misleading the mind.-Perceptions will make themselves perceptible to the accurate observer, $\&$ unless the laws of human nature should undergo alterations the facts which form the basis of every science must be similarly discerned \& similarly reasoned upon by men who are disenchanted with regard to every thing but fact. ${ }^{49}$

"The feeling generally connected with new facts," he concludes, enables the mind "to reason more rapidly upon them," but it also encourages theorists "to perceive analogies where analogies to the sound mind do not exist." ${ }^{50}$ Science is presented in this note as a factual and rational enterprise, the work of a "sound mind" that accurately observes and reasons on "things in their real light." Davy's opinion of imaginative theorising here is unambiguously negative: it yields nothing but "illusions" that mislead the mind, and his final sentence implies that analogies are chief among these illusions. More often than not, he suggests, the perception of analogies emerges not from facts themselves but from the tendency of the theorising mind, when contemplating facts, to be carried away by an irrational enthusiasm.

Davy reiterated this point a quarter of a century later, in a poem which he wrote in 1827 in the Italian city of Ravenna and which was printed posthumously in John Davy's Memoirs:

In ignorance of all things we assume

What reasonings most please us, and in things

The most unlike in form as well as essence

We trace analogies; as if it were

A joy to blend all contrarieties,

\footnotetext{
49 Davy, RI MS HD/20C, Royal Institution, 59.

${ }^{50}$ Davy, RI MS HD/20C, 60.
} 
And to discover

In things the most unlike some qualities

Having relationship and family ties..$^{51}$

The tracing of analogies is attributed in these lines to ignorant "reasonings" rather than to the imagination, but apart from this difference in language the poem's argument is almost identical to that of Davy's 1800 note. Analogies are founded not on objective facts or material things but on a feeling, a pleasing "joy," that prompts the mind of the observer to contrive connections and to impose similarities on unlike things. This interpretation of analogy as a mental artifice throws doubt on the existence of real correspondences in the external world and on Davy's claim in the Elements of Chemical Philosophy that "analogy of properties is connected with analogy of composition." Davy's science writing consistently indicates that chemistry as an intellectual discipline is directed by the assumption of the uniformity of natural processes. This poem, conversely, characterises the discovery of such uniformity as a projection of the mind, while emphasising, in contrast, the irreducible heterogeneity of nature.

The poem starts as an attack on analogy in general, but its disapproval promptly focuses, like that of the Unknown in Consolations in Travel, specifically on analogies between inanimate and living things. In another example of his distrust of comparisons based on words, Davy claims that the ignorance of analogical thinking is exemplified in a conventional but misleading figure of speech:

Thus life we term a spark, a fire, a flame;

And then we call that fire, that flame, immortal,

Although the nature of all fiery things

Belonging to the earth is perishable.

\footnotetext{
${ }^{51}$ Quoted in John Davy, Memoirs of the Life of Sir Humphry Davy, 334.
} 
The lightning, in its fierceness and its power,

Is of an instant only!

The meteor's blaze lightening the visible scene

As transient is!

And vainly should we search where these had been.

The solar light, when the bright orb has sunk,

Dwells not within known space;

And that which kindleth the whole frame of nature

Has no abiding place, although its source

Is everlasting: it lives but to decay,

And in its course a million miles are nothing;

It passes from and through the infinite. ${ }^{52}$

The problem here, it seems, is not with the metaphor which identifies life as a fire or flame, but with the analogy which erroneously attributes to living beings and "fiery things" the same property: immortality. The poem's rejection of this claim, though, itself depends on a loose analogy between a group of phenomena that are arguably more dissimilar than similar: fire, lightning, the trajectory of a meteor, and the transmission of light from the sun and from stars across the universe ("that which kindleth the whole frame of nature"). The property which connects these phenomena, according to Davy, is their transience. Like his other writings, the poem depicts nature as dynamic and mutable, but whereas his writings on chemistry claim that this mutability can be reduced to a regular and quantifiable order, here it is instead indicative of impermanence and decay. This argument is also communicated in another kind of analogy, between Davy's pessimistic interpretation of natural processes - and of the mind's tendency to establish false analogies between them — and the fragmentary form of his

\footnotetext{
52 John Davy, Memoirs of the Life of Sir Humphry Davy, 334.
} 
blank verse, which is frequently interrupted by half-finished lines. The lines of the poem are as "unlike in form" as its figures of speech are unlike in essence; both are haphazard and contingent. Although Davy identifies the source of light (and it is not clear whether he means a physical body or a metaphysical deity) as everlasting, the poem suggests that nothing else, either in nature or in language, is permanent.

In the final lines, however, he tries to console himself on this point by altering the terms of his argument:

So is our life of thought: we look not back

Beyond a few short hours, - - life, a day,

An age; that period gone, we blend

With future, and with past, eternity. ${ }^{53}$

This anti-analogy poem ends with an analogy which is even more speculative than the one it has just rejected. It may be misleading to claim that inanimate and living things share the property of immortality, but in these lines Davy puts forward the same analogical claim about physical phenomena and "our life of thought." He implies that, although natural processes and personal and historical memories appear to be transient, they similarly emerge from and are incorporated within something (presumably the divine) which transcends the limits of measurable space and time: spatial infinity is to light as temporal eternity is to thought.

The contradictions in this argument can be read in biographical terms: Davy had been seriously ill for several months when he wrote the poem, and it is easy to see why he may have wanted to find a means of voicing both his fears and his hopes about immortality. However, the poem's fluctuations are also expressive of a considered intellectual stance that informed his work throughout his career; it sets out a measured assessment of analogy which it shares with his writings on chemistry. For Davy, poetic expression and scientific theory

\footnotetext{
53 John Davy, Memoirs of the Life of Sir Humphry Davy, 334.
} 
both depend on analogy in their elaboration of imaginative and synthetic links between physical phenomena and between the physical and the metaphysical. But the poem also restates Davy's habitual warning about analogy's tendency to exceed the facts of nature, to hypothesise figurative relations that cannot be verified. Davy tried throughout his career to police the boundary between factual and figurative analogies, but his work as a whole indicates that the epistemological value of analogy is inseparable from its speculative abandon. While Erasmus Darwin distinguished between the "looser analogies" of poetry and the "stricter ones" of natural philosophy, Davy's diverse writings complicate this distinction by suggesting that poetic and scientific knowledge are each examples of an inductive method which is at the same time empirical and imaginative.

Gregory Tate is a lecturer in Victorian literature at the University of St Andrews. His research concentrates on the links between literature (especially poetry), science, and philosophy in nineteenth-century Britain. This article forms part of a larger project, titled "Poetical Matter" and partly funded by a British Academy Mid-Career Fellowship, which examines the exchange of methods, theories, and language between poetry and the physical sciences in the nineteenth century. Email: gpt4@standrews.ac.uk. 